\title{
COMPARAÇÃO ENTRE VALORES HEMATOLÓGICOS (HEMOGLOBINA, HEMATÓCRITO E FERRO SÉRICO) DA PARTURIENTE E DO RECÉM-NASCIDO
}

Szarfarc, S. C. - Comparação entre valores hematológicos (hemoglobma, hematócrito e ferro séricos da parturente e do recém-nascido. Rev. Saúde públ., S. Paulo, 9:43-7, 1975 .

REsLmo: São bastante contraditórias as informaçoes a respeito do relacionamento entre indices hematológicos maternos e fetais. Com o objetivo de comparar as condiçoes hematológicas maternas com aquelas do feto, foi feito estudo broquimico no sangue de parturientes e respectiros recém-nascidos. A analise estatistica dos resultados obtidos nos testes de correlaçāo e de diferença de médias permitem sugerir que a valores mais elevados de hemoglobina, hematócrito e ferro sérico da mãe. corresyondem ralores mais elevados de hemoglobina, hematócrito e ferro sérico no feto.

Unitermos: Indices hematológicos. Recém-nascidos. Parturente.

\section{NT RODLCAO}

Apesar de serem numerosas as referências à elevada prevalência de deficiência de ferro na gestante e à sua associação com outros estados patológicos da gravidez. um ponto que permanece contraditório é o da influência que o ferro orgânico da mãe exerce sobre as condições hematológicas do filho.

Com o objetivo de verificar esse aspecto. estudamos alguns indices hematológicos em parturientes e recém-nascidos.

\section{MATERIAL E MÉTODOS}

O sangue renoso de 260 gestantes a termo foi colhido durante o trabalho do parto. O sangue de 219 recém-nascidos foi colhido na extremidade placentária do cordão umbilical. imediatamente após a expulsão do feto.

Essa amostra de parturientes e de recém-nascidos faz parte da população assistida pela Casa Maternal e de Assistência à Infância. da Legião Brasileira de Assistência.

As dosagens hioquímicas foram feitas adotando-se os seguintes métodos:

- Hemoglobina - método de cianometahemoglobina. usando-se o padrão artificial de hemoglobina de Ventura e col. " como referềncia.

-... Hematócrito - centrifugação por 5 min em tubos capilares.

Do Departamento de Xutriça da Faculdade de Saúde Püblica da Lnıversidade de Sảo Paulo - Av Dr. Arnaldo, 715 - São Paulo, SP - Brasil 
SZARFARC, S.C. - Comparação entre valores hematológicos (hemoglobina, hematócrito e ferro sérico) da parturiente e do recém-nascido. Rev. Saúde pübl., S. Paulo, 9:43-7, 1975.

- Ferro sérico - método de Bothwell e Mallet ${ }^{1}$ adaptado para volumes semimicro.

\section{R ESULTADOS}

Aplicamos aos valores de hemoglobina, hematócrito e ferro sérico das mães e respectivos filhos, testes de correlação. Sendo a concentração de hemoglobina o valor mais usado na detecção de anemia, correlacionamos esse índice com os de hematócrito e ferro sérico, respectivamente para mães e filhos (Tabela 1 ).

Todas as correlações se mostraram positivas e significantes.

São poucas as referências sobre limites de normalidade para valores hematológicos das parturientes e recém-nascidos. É lícito, no entanto, esperar que gestantes não anêmicas tenham maior chance de ter estoques adequados de ferro e assim prover adequadamente o feto. Por essa razão, dividimos nossa amostra de gestantes em dois grupos segundo o critério: a. formado por mulheres anêmicas $(\mathrm{Hb}<12,0 \mathrm{~g} / 100 \mathrm{ml} \mathrm{e}$ ou $\mathrm{Ht}<35 \%$ )

b. formado por mulheres não anêmicas $(\mathrm{Hb}=12,0 \mathrm{~g} / 100 \mathrm{ml} \mathrm{e}$ ou $\mathrm{Ht} \equiv 35 \%$ )

Os valores hematológicos médios obtidos para esses dois grupos de mães e respectivos filhos, foram comparados (Tabela 2) através do teste de diferença de duas médias. A média obtida para as concentrações de ferro sérico no grupo formado por mães anêmicas foi significativamente menor do que a obtida entre mães não anêmicas. $O$ mesmo ocorreu em relação à hemoglobina e ao hematócrito de recémnascidos, cujos valores médios foram significantemente maiores no grupo formado por mães não anêmicas (teste monocaudal - $\alpha=5 \%$ ). As médias de concentração de ferro sérico de recém-nascidos distribuídos segundo o critério de anemia da mãe, não se mostraram significantemente diferentes).

T A B E L A 1

Correlação entre valores hematológicos de parturientes e recém-nascidos

\begin{tabular}{|c|c|c|c|c|c|c|}
\hline $\mathrm{n}$ & & $\mathrm{x}$ & & & $r$ & to \\
\hline 187 & $\mathrm{Hb}$ & $(\mathrm{G})$ & $\mathrm{Hb}$ & $(\mathrm{RN})$ & 0,39 & 5,76 \\
\hline 184 & $\mathrm{Ht}$ & $(\mathrm{G})$ & $\mathrm{Ht}$ & $(\mathrm{RN})$ & 0,38 & 5,54 \\
\hline 187 & FS & $(\mathrm{G})$ & $F S$ & $(\mathrm{RN})$ & 0.32 & 4,58 \\
\hline 260 & $\mathrm{Hb}$ & $(\mathrm{G})$ & $\mathrm{Ht}$ & $(\mathrm{G})$ & 0,77 & 19,30 \\
\hline 187 & $\mathrm{Hb}$ & ( $G)$ & $\mathrm{FS}$ & $(\mathrm{G})$ & 0,20 & 2,78 \\
\hline 219 & $\mathrm{Hb}$ & $(\mathrm{RN})$ & $\mathrm{Ht}$ & $(\mathrm{RN})$ & 0,76 & 17,22 \\
\hline 213 & $\mathrm{Hb}$ & $(\mathrm{RN})$ & FS & $(\mathrm{RN})$ & 0.41 & 6.51 \\
\hline
\end{tabular}

$\begin{aligned} \mathrm{Hb} & =\text { hemoglobina } \\ \mathrm{Ht} & =\text { hematócrito } \\ \mathrm{FS} & =\text { ferro sérico } \\ \mathrm{n} & =\mathrm{n} \cdot 0^{\circ} \text { de individuos }\end{aligned}$

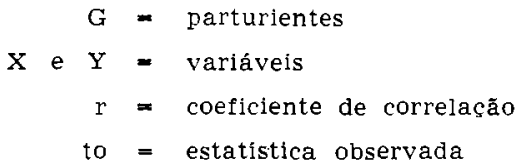


SZARFARC, S.C. - Comparação entre valores hematológicos (hemoglobina, hematócrito e ferro sérico) da parturiente e do recém-nascido. Rev. Saúde puibl., S. Paulo, 9:43-7, 1975.

TABELA 2

Teste de diferença das médias de ferro sérico da gestante e hemoglobina, hematócrito e ferro sérico dos recém-nascidos, distribuidos segundo presença de anemia na mãe

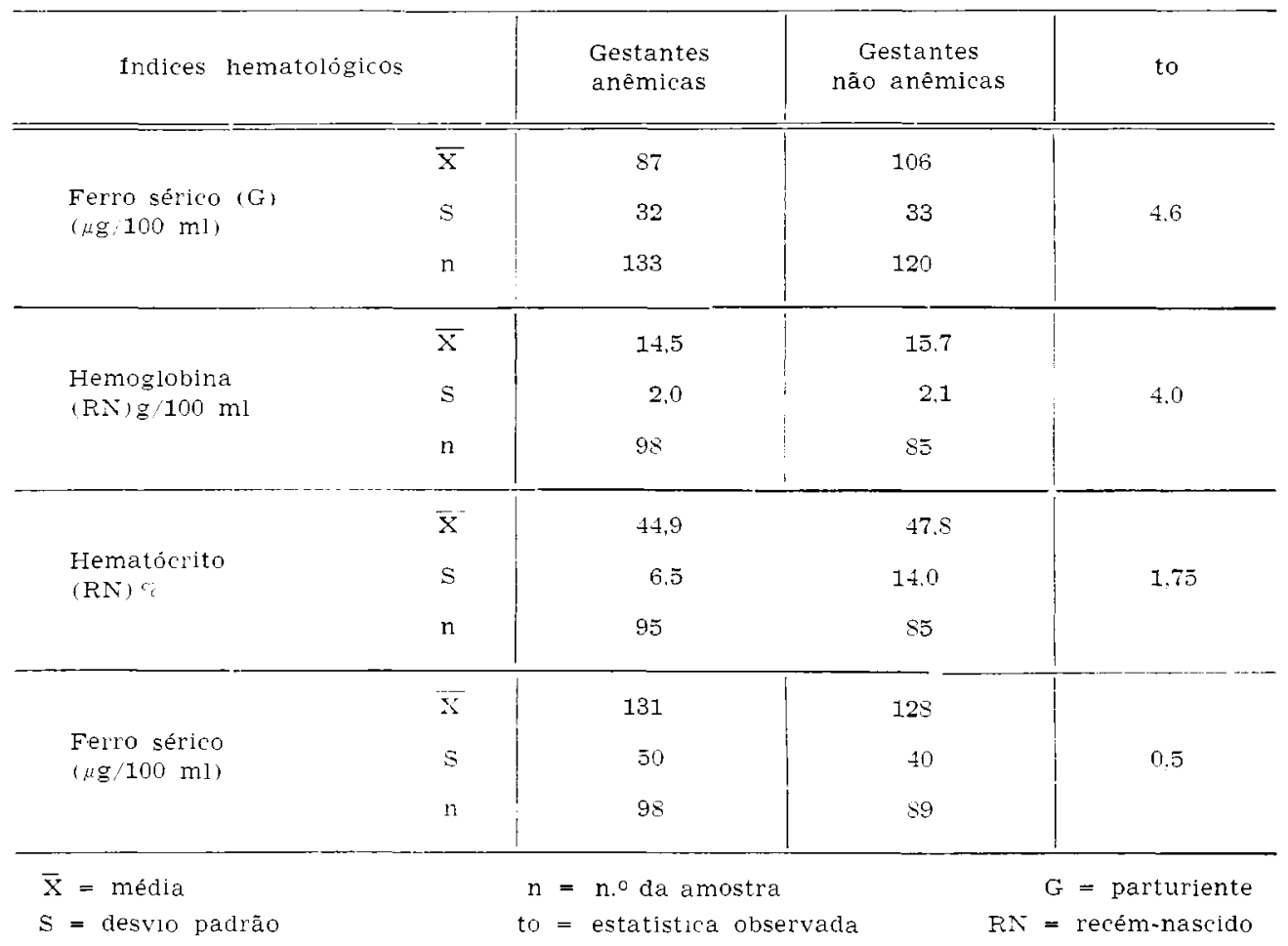

\section{COMENTARIOS}

São bastante contraditórias as informações a respeito do relacionamento entre indices hematológicos maternos e fetais.

Segundo De Leeuw e col. ${ }^{3}$. as demandas de ferro do feto são atendidas prioritariamente às da mãe. sendo esta a única a sentir as consequiências imediatas de uma absorção insuficiente de ferro.

Rowland ' não observou correlação entre as concentrações de hemoglobina materna e a fetal. Iqualmente Loria e col. ${ }^{*}$ não observaram correlação significante entre valores hematológicos maternos e fetais.

Por outro lado Brewer" relaciona o estado nutricional da mãe e do concepto ao afirmar que a dieta da mãe é a dieta do filho.

As correlações que testamos (Tabela 1) foram positivas e significantes. Assim, podemos dizer que a valores mais elevados de hemoglobina materna. correspondem valores mais altos de hemoglobina fetal, o mesmo acontecendo com os valores de hematócrito e ferro sérico. Igualmente podemos dizer que a valores mais elevados de hemoglobina materna correspondem valores mais elevados de hematócrito e ferro sérico maternos e que a valores mais elevados de hemoglobina fetal correspondem valores mais elevados de hematócrito e ferro sérico fetais.

Havíamos observado que a prevalência 
SZARFARC, S.C. - Comparação entre valores hematológicos (hemoglobina, hematócrito e ferro sérico) da parturiente e do recém-nascido. Rev. Saúde públ., S. Paulo, 9:43-7, 1975.

de anemia é muito maior na mãe do que no recém-nascido, o que sugeriria uma espoliação da mãe pelo filho ${ }^{8}$. As correlações que encontramos não invalidando a sugestão acima, quantificam o fenômeno que quizemos analisar.

O baixo grau de correlação entre hemoglobina e ferro sérico das gestantes seria explicado pela mobilização de ferro na gravidez, que se desenvolve primeiramente por uma diminuição de ferro circulante, seguida, em muitos casos, pelo aparecimento de anemia ferropriva, mesmo em mulheres com estoques satisfatórias desse elemento.

Embora uma correlação estatística não signifique uma relação causa-efeito, o conjunto de correlações positivas encontradas, sugere que há relativa redução concomitante de todos os índices fetais em função desses índices maternos. Vale dizer que se for fornecido, em tempo hábil, quantidade adequada de ferro à mãe, todos os valores hematológicos deverão ser influenciados favoravelmente. A importância desse evento é salientada quando nos reportamos à Mollison e Cutbush ${ }^{5}$ que referem uma evidente relação positiva entre valor de hemoglobina de uma criança ao nascer e sobrevida dessa criança.

Procuramos avaliar o comportamento da hemoglobina, hematócrito e ferro sérico dos recém-nascidos em relação à presença ou ausência de anemia na mãe (Tabela 2). Encontramos que as concentraçōes de hemoglobina e hematócrito fetais são sig- nificantemente mais altas no grupo formado por mães não anêmicas.

Apesar de termos encontrado correlação significante entre valores de ferro sérico materno e fetal em relaçấo às médias, - ferro sérico fetal distribuído segundo presença de anemia na mãe, não apresentou diferença. Talvez pudéssemos explicar esse evento pelo fato de que, como quer Morison ${ }^{6}$ o ferro sérico reflete mais a reserva marcial tissular do que a transferência desse elemento da mãe ao feto através da placenta.

\section{CONCLUSOES}

Dos resultados obtidos nas análises bioquímicas de sangue de parturientes e recém-nascidos visando verificar o relacionamento dos níveis hematológicos, concluímos:

1. as correlações encontradas entre os índices hematológicos maternos e fetais (Tabela 1) foram positivos e significantes;

2. os valores médios de ferro sérico materno e hemoglobina e hematócrito fetal foram significativamente menores no grupo formado por gestantes anêmicas;

3. não foi encontrada diferença entre os valores médios de ferro sérico fetal, distribuídos segundo o critério anemia na mãe.

RSPU-B/246

Szarfarc, S. C. - [Comparison between hematological values of the mother and newborn. Rev. Saúde públ., S. Paulo, 9:43-7, 1975.

SUMMARY: Information on the relationship between hematological indices of mother and nowborn is contradictory. In order to compare the mentioned indices, the present study was carried out. The results of our study show that the higher the hematologic indices in the mother the higher the hematologic indices in the newborn.

UnIterms: Hematologiacal indices. Newborn. Pregnant. 
SZARFARC. S.C. - Comparacăo entre valores hematológicos (hemoglobına, hematócrito e ferro sérico) da parturiente e do recém-nascido. Rev. Salide pibl.. S Paulo, 9:43-7, 1975.

\section{REFERENTCIAS BIBLIOGRÁFICAS}

1. BOTHWELL, T.H. \& MALLET, B. The determination of iron in plasma or serum. Brochem. J, 59:599-602, 1955 .

2. BREWER, T. - Human pregnancy nutrition, a clinical view. Obstet. Gynec., $30: 605-7,1967$.

3. DE LEELW, N.K.M. et al. -- Iron deficiency and hydremia in normal pregnancy. Medicune, Baltimore, 45:291315, 1966 apud Excerpta Hed. Sect i. Obst. Gynecol, $20: 315,1967$.

4. LORIA, A, et al - Comparación entre el estado nutricional de la madre $y$ del recién nascido. Gac. med her. 99:229-39, 1969 .

5. MOLLISON, P.L. \& CLTBLSH, N. - A method of measuring the severity of a series of cases of hemolityc disease of the nerworn. Blood, 6:777-88, 1951.
6. MORISON, J.E. - Patologia fetal y neonatal. Barcelona, Editorial Pediatrica. 1972 .

7. ROWLAND. H.A.K. - The relationship between the hemoglobin concentration of mother and infant at delivery. J. trop. Pedlat, 14:8-9, 1968.

8. SZARFARC, S.C. - Anemia ferropriva em parturientes e recém-nascidos. Rev. Saúde pibl, S. Paulo. 8:369-74. 1974.

9. VENTLRA, F. et al - Hemoglobina: dosagem pelo método de cianometahemoglobina. t'so de solução artificial para calibração dos aparelhos colorimétricos. Rev. Hosp. Clln. Fac. Med. S. Paulo, :?:303-4, 1967.

Recebido para publicacio em 13-12-r4

Aprovado para publicacio em 1,-01-\%o 